\title{
ON THE UNIFORM CONSISTENCY OF FREQUENCY POLYGONS FOR $\rho^{-}$-MIXING SAMPLES
}

\author{
Wei Wang, HaiWu Huang, Yi Wu And Kan Chen*
}

\begin{abstract}
In this paper, the frequency polygon is considered as a nonparametric density estimator for $\rho^{-}$-mixing samples. By the moment inequality, we prove the uniformly strong consistency of the estimator and obtain the corresponding rate under some mild conditions. The results obtained in this paper extend and improve some existing ones in the literature.
\end{abstract}

Mathematics subject classification (2020): 62G05.

Keywords and phrases: Uniformly strong consistency, $\rho^{-}$-mixing samples, Frequency polygon.

\section{REFERENCES}

[1] N. BeSAID, S. DABo-NiAng, Frequency polygons for continuous random fields, Statistical Inference for Stochastic Processes, 10: 55-80 (2010).

[2] M. Carbon, B. Garel, L. T. Tran, Frequency polygons for weakly dependent processes, Statistics and Probability Letters, 33: 1-13, (1997).

[3] M. CARbon, C. FrancQ, L. T. TRAn, Asymptotic normality of frequency polygons for random fields, Journal of Statistical Planning and Inference, 140 (2): 502-514, (2010).

[4] H. W. Huang, J. Y. Peng, X. T. Wu, B. WANG, Complete convergence and complete moment convergence for arrays of rowwise ANA random variables, Journal of Inequalities and Applications, Article ID: 72, (2016).

[5] K. JoAg-Dev, F. Proschan, Negative association of random variables with applications, Annals of Statistics, 11 (1): 286-295, (1983).

[6] D. W. ScotT, Frequency polygons: theory and application, Journal of the American Statistical Association, 80 (390): 348-354, (1985).

[7] X. J. WAnG, Y. Wu, S. H. Hu, The Berry-Esseen bounds of the weighted estimator in a nonparametric regression model, Annals of the Institute of Statistical Mathematics, 71, 1143-1162, (2019).

[8] J. F. WANG, F. B. LU, Inequalities of maximum partial sums and weak convergence for a class of weak dependent random variables, Acta Mathematica Sinica, English Series, 22 (3): 693-700, (2006).

[9] G. D. XING, S. C. YANG, X. LiAnG, On the uniform consistency of frequency polygons for $\psi-$-mixing samples, Journal of the Korean Statal Society, 44 (2): 179-186, (2015).

[10] G. D. XING, S. C. YANG, Uniformly strong consistency of frequency polygons for negatively associated samples, Communications in Statistics-Simulation and Computation, 46 (3): 2168-2175, (2015).

[11] L. X. ZHANG, A functional central limit theorem for asymptotically negatively dependent random fields, Acta Mathematica Hungarica, 86 (3): 237-259, (2000).

[12] L. X. ZHANG, Central limit theorems for asymptotically negatively associated random fields, Acta Mathematica Sinica, English Series, 16 (4): 691-710, (2000).

[13] Y. ZHANG, Complete moment convergence for moving average process generated by $\rho^{-}-$-mixing random variables, Journal of Inequalities and Applications, Article ID: 245, (2015).

[14] L. X. ZHANG, X. Y. WANG, Convergence rates in the strong laws of asymptotically negatively associated random fields, Applied Mathematics-A Journal of Chinese Universities, Series B, 14 (4): 406-416, (1999). 